\title{
Further studies on the role of IL-12 in Pseudomonas aeruginosa corneal infection
}

LD Hazlett, X Huang, SA McClellan and RP Barrett

rescue susceptible $\mathrm{B} 6$ mice from corneal perforation after bacterial challenge.

Eye (2003) 17, 863-871. doi:10.1038/

sj.eye. 6700558

Keywords: cytokines; inflammatory mediators; cornea; bacterial infection; mice; pathogenesis

\section{Introduction}

Pseudomonas aeruginosa (P. aeruginosa) infection develops rapidly, destroying the cornea, with a higher incidence of disease in extended-wear contact lens users. ${ }^{1}$ Studies from our laboratory have provided mounting evidence that a CD4+ $\mathrm{T}$ cell (Th1)-dominated response following $P$. aeruginosa corneal infection is associated with susceptibility and corneal perforation in C57BL/6 (B6) mice, and that IFN- $\gamma$ is involved, at least partially, in this process. ${ }^{2}$ Other inbred strains of mice favouring a Th1 response, such as C57BL/10 and B10.D2/nSn, are also susceptible to infection, ${ }^{3}$ suggesting that CD4+ $\mathrm{T}$ cells and a Th1-dominant cytokine profile in mice infected with $P$. aeruginosa are predictive of corneal destruction and poor disease outcome.

Development of a Th1 response classically depends upon the presence of IL-12 as well as the ability of $\mathrm{T}$ cells to respond to this cytokine. ${ }^{4-6}$ IL-12 is functionally pleiotropic and exhibits a number of bioactivities that may modulate infectious disease progression, including enhancing proliferative and cytotoxic activity of NK and T cells, inducing Th1 T cell differentiation, and influencing the production of other immunoregulatory cytokines, particularly IFN- $\gamma$ and TNF- $\alpha$. IL-12 has been localized in the cornea of B6 mice after P. aeruginosa infection, ${ }^{7}$ but is not present in similarly infected BALB/c mice. ${ }^{8}$ However,

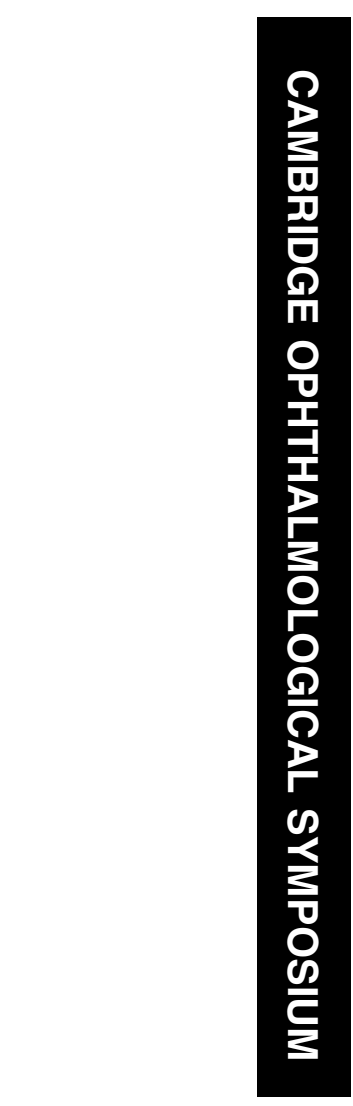

Department of Anatomy/ Cell Biology

Wayne State University School of Medicine Detroit, MI, USA

Correspondence: LD Hazlett

Department of Anatomy/ Cell Biology

Wayne State University School of Medicine 540 East Canfield Avenue Detroit, MI 48201, USA Tel: + 13135771079

Fax: + 13135773125

E-mail: Ihazlett@ med.wayne.edu

Received: 28 February 2003 Accepted in revised form: 28 February 2003

Grant support: NEI R01EY02986 and P30EY04068

Proprietary interest: Nil production, with a concomitant reduction in IL-4 levels; and that injected rIL-4 fails to 
whether or not BALB/c mice are capable of responding to exogenous IL-12 and whether after such treatment the disease response is altered, remain unknown and were addressed by this study. Since neutralization of IFN- $\gamma$, a predominant Th1-type cytokine, before infection in B6 mice prevented corneal perforation, ${ }^{2}$ we elected to test the expression of this cytokine in the cornea of infected rIL-12-treated BALB/c mice. TNF- $\alpha$, another proinflammatory cytokine induced by IL-12, was also examined. Alternatively, since levels of IL- 4 were decreased after rIL-12 injection of BALB/c mice, the neutralizing effect of this anti-inflammatory cytokine was tested in B6 mice to determine if injection of rIL-4 ameliorated disease in susceptible mice.

\section{Materials and methods}

\section{Infection of mice}

Female B6 and BALB/c mice (8-week-old) were purchased from The Jackson Laboratories (Bar Harbor, ME, USA) and maintained in an isolator unit. Before corneal infection, mice were anaesthetized with isoflurane (Aerrane, Anaquest, Madison, WI, USA) and placed beneath a stereoscopic microscope at $\times 40$ magnification. Using a sterile $255 / 8$-gauge needle, the central cornea of the left eye was scarified with three 1 $\mathrm{mm}$ incisions. A $5 \mu \mathrm{l}$ bacterial suspension containing $1.0 \times 10^{6}$ colony forming units (CFU) of P. aeruginosa, American Type Culture Collection (ATCC) strain 19660, prepared as described before, ${ }^{2}$ was topically applied onto the scarified cornea. Eyes were examined macroscopically at $24 \mathrm{~h}$ postinfection (p.i.) and at times described below to ensure that all mice were similarly infected and to monitor the course of disease, respectively. All animals were treated humanely and in full compliance with The Association for Research in Vision and Ophthalmology (ARVO) resolution on usage and treatment of animals in ocular research.

\section{Ocular response to infection}

After bacterial infection, ocular disease was graded using an established scale: ${ }^{9} 0$, clear or slight opacity partially covering the pupil; +1 , slight opacity fully covering the entire anterior segment; +2 , dense opacity partially or fully covering the pupil; +3 , dense opacity covering the entire anterior segment; and +4 , corneal perforation. Five mice from each experimental group (rIL-12 or rIL-4 $v s$ vehicle-treated) were examined at 1,3 , and 5 days p.i. A mean clinical score was calculated for each group of mice to express disease severity. ${ }^{2,3}$

\section{Immunostaining}

Normal uninfected eyes from BALB/c and B6 mice were enucleated ( $n=3$ eyes/group) and embedded in Tissue Tek Optimal Cryogenic Temperature (OCT) compound (Miles, Elkhart, IN, USA), snap frozen in liquid nitrogen, and stored at $-70^{\circ} \mathrm{C}$ before immunostaining. Frozen sections $(10 \mu \mathrm{m}$ in thickness) of cornea were cut on a Microm cryostat (Fisher Scientific, Itasca, IL, USA). Before immunostaining, sections were stored at $37^{\circ} \mathrm{C}$ overnight and then fixed in cold acetone at $-20^{\circ} \mathrm{C}$ for $2 \mathrm{~min}$ and washed with $0.01 \mathrm{M}$ PBS, 2-3 times. Sections were covered with PBS containing 1\% BSA and $0.05 \%$ Tween-20 in a moist chamber for $30 \mathrm{~min}$ to block nonspecific binding. Afterwards, sections were incubated for $1 \mathrm{~h}$ with a primary goat anti-mouse $\mathrm{Ab}$ specific for IL-12 p40 (Santa Cruz Biotechnology, Inc., Santa Cruz, CA, USA) (1:100 dilution), followed by a $30 \mathrm{~min}$ incubation with $0.3 \%$ hydrogen peroxide $\left(\mathrm{H}_{2} \mathrm{O}_{2}\right)$ to block endogenous peroxidase. Sections were incubated for $1 \mathrm{~h}$ with a rabbit anti-goat biotinylated secondary antibody in Tris- $\mathrm{HCl}$ buffer with $0.1 \%$ Tween-20 in a moist chamber. Horseradish peroxidase-conjugated avidin ( 1 : 50 dilution; Zymed, San Francisco, CA, USA) was incubated with the sections for $30 \mathrm{~min}$ and immunoreactive cells were visualized after colour development for $15 \mathrm{~min}$ with 3,3'-diaminobenzidine tetrahydrochloride (Pierce, Rockford, IL, USA). Between incubations, slides were washed with PBS and drained dry. Sections were counterstained with Gill's haematoxylin (Polyscience, Warrington, PA, USA) and cleared with a modified mountant containing $10 \%$ glycerol and $1 \% p$-phenylenediamine dihydrochloride.

\section{RT-PCR}

Corneas were removed from BALB/c mice at 3 and 5 days p.i., frozen in liquid nitrogen, and stored at $-80^{\circ} \mathrm{C}$. Frozen samples were homogenized in RNA STAT-60 (Tel-Test, Friendsville, TX, USA) and total RNA was isolated following the manufacturer's instruction. Total RNA (100 ng) was reverse transcribed using oligo(dT) primers (GIBCO BRL, Grand Island, NY, USA) and reverse transcriptase (Invitrogen) in the presence of $10 \mathrm{U}$ of RNase inhibitor (Promega, Madison, WI, USA). Amplification of cDNA was carried out with Taq polymerase (GIBCO BRL) and specific primers for IFN $-\gamma$, TNF- $\alpha$, IL-4, and $\beta$-actin in a GeneMate Thermal Cycler (ISC BioExpress, Kaysville, UT, USA). Cycling conditions were $94^{\circ} \mathrm{C}$ for $40 \mathrm{~s}, 60^{\circ} \mathrm{C}$ for $50 \mathrm{~s}, 72^{\circ} \mathrm{C}$ for $1 \mathrm{~min}$ for 42,30 , and 32 cycles for IFN- $\gamma$, TNF- $\alpha$, and IL-4, respectively, and a final extension at $72^{\circ} \mathrm{C}$ for $10 \mathrm{~min}$. The primers used were $5^{\prime}$-TGC ATC TTG GCT TTG CAG CTC TTC CTC ATG GC-3' (sense) and 5'-TGG ACC TGT GGG TTG 
TTG ACC TCA AAC TTG GC-3' (antisense) for IFN- $\gamma$; 5'-GCA AGC TTC GCT CTT CTG TCT ACT GAA CTT CGG-3' (sense) and 5'-GCT CTA GAA TGA GAT AGC AAA TCG GCT GAC GG-3' (antisense) for TNF- $\alpha$; 5'-GGG GGG ATT TGT TAG CAT CTC TTG-3' (sense) and 5-CAC TCT CTG TGG TGT TCT TCG TTG C-3' (antisense) for IL-4; and 5'-GTG GGC CGC TCT AGG CAC CAA-3' (sense) and 5'-CTC TTT GAT GTC ACG CAC GAT TTC-3' (antisense) for $\beta$-actin, respectively. Control RT-PCR without reverse transcriptase during RT was carried out to confirm the lack of DNA contamination in the total RNA samples. A volume of $20 \mu \mathrm{l}$ of final PCR products was analysed by electrophoresis on $1.2 \%$ agarose gels stained with ethidium bromide.

Reactive bands were visualized under UV transillumination and quantitated using an AlphaImager 2000 Documentation and Analysis system (Alpha Innotech Corporation, San Leandro, CA, USA). Integrated density values (IDV) for IFN $-\gamma, \mathrm{TNF}-\alpha$, and IL-4 PCR products were corrected for the amount of $\beta$-actin on each sample and data are expressed as the mean IDV of samples from five separate mice for each experimental time point.

\section{Recombinant cytokine treatment}

Recombinant murine IL-12 and IL-4 were purchased from PeproTech (Rocky Hill, NJ, USA). BALB/c and B6 mice ( $n=5$ /group) were injected i.p. three times (1 day before and 1 and 3 days p.i.) with $1 \mu \mathrm{g}$ rIL-12 (BALB/c) or rIL-4 (B6) diluted in 0.05\% PBS/BSA (vehicle). Control mice for each group similarly received an equal volume of vehicle.

\section{Histopathology}

Eyes ( $n=3$ /group) were enucleated at 5 and 7 days p.i. from rIL-12 vs PBS/BSA-treated BALB/c mice and rIL-4 vs PBS/BSA-treated B6 mice. Eyes were immersed in PBS, rinsed and placed in a fixative containing $1 \%$ osmium tetroxide, $2.5 \%$ glutaraldehyde, and $0.2 \mathrm{M}$ Sorenson's phosphate buffer ( $\mathrm{pH} 7.4)(1: 1: 1)$ at $4{ }^{\circ} \mathrm{C}$ for $3 \mathrm{~h}$. Eyes were dehydrated in graded ethanols and embedded in Epon-araldite as described. ${ }^{2}$ Thick sections $(1.5 \mu \mathrm{m})$ were cut, stained with a modified Richardson's stain, and observed. Representative sections were photographed using a Zeiss Axiophot microscope (Carl Zeiss, Morgan Instruments, Inc., Cincinnati, OH, USA). ${ }^{2}$

\section{Statistical analysis}

An unpaired, two-tailed Student's t-test was used to determine statistical significance for data from RT-PCR and mean clinical score analyses. Differences (mean \pm SEM) were considered significant at $P \leq 0.05$. All experiments were repeated at least twice to ensure reproducibility, and representative data from a single experiment are shown.

\section{Results}

\section{Immunostaining}

Previous experiments from this laboratory have provided evidence that IL-12 mRNA transcripts and protein were detectable in the cornea of B6 but not BALB/c mice following infection. ${ }^{7,8}$ However, constitutive expression of IL-12 p40 and its distribution in the cornea had not been tested before. Figure 1(a and b) shows immunostaining for IL-12 p40 in normal, uninfected B6, and BALB/c mouse cornea. Surprisingly, positive immunostaining for IL-12 p40 was detected in the corneal epithelium of uninfected B6 mice. Predictably, no staining was seen in the cornea of similarly treated BALB/c mice.

\section{rIL-12-treated BALB/c mice}

To ascertain whether BALB/c mice were able to respond to IL-12, they were injected with rIL-12 or PBS/BSA
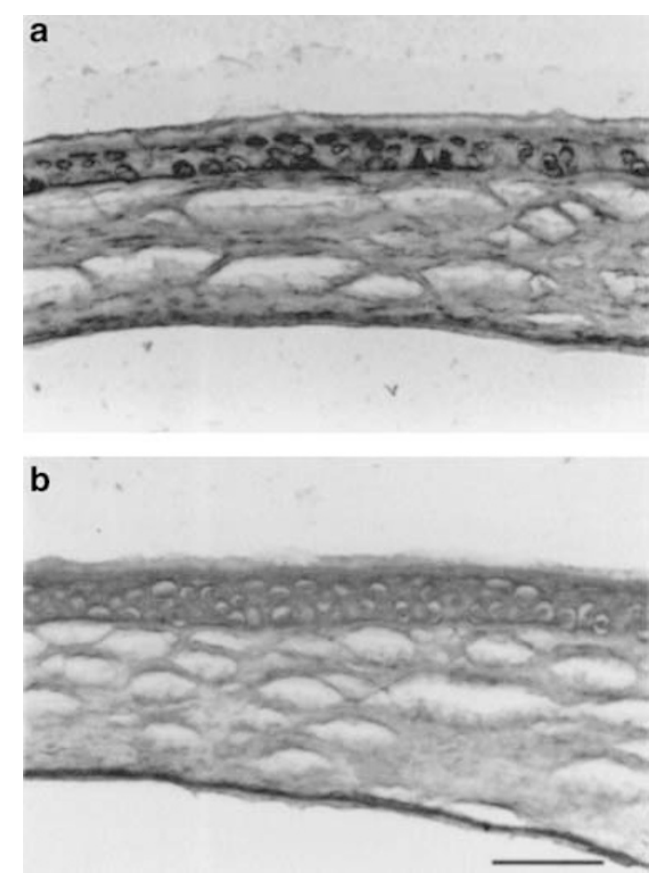

Figure 1 Immunostaining for IL-12 p40 in the normal, uninfected cornea of B6 and BALB/c mice. IL-12 p40 was detected in the cornea of uninfected B6 (a), but not BALB/C (b) mice. Magnification $\times 100($ bar $=50 \mu \mathrm{m})$. 
(vehicle), and ocular disease response differences were monitored after $P$. aeruginosa challenge. The data are shown in Figure 2. At 1 day p.i., no significant difference $(P=0.15)$ was observed in the cornea of the rIL-12injected when compared with vehicle-treated mice. A significant difference was observed in mean clinical scores between rIL-12 vs vehicle-treated mice at 3,5, and 7 days p.i. $(P=0.018,0.0016$, and 0.001 at 3,5 , and 7 days p.i., respectively). At these later times, all rIL-12-injected mice exhibited a similar increased mean clinical score $(+3$ to +4$)$ indicating worsening of disease, while the cornea of vehicle-treated mice remained similar in appearance to the slight level of opacity observed at 1 day p.i. By 7 days p.i., all the corneas of rIL-12-treated mice had perforated $(+4)$ while corneas of vehicle-treated mice began to clear.

\section{Slit lamp and histopathology}

Corneas from rIL-12 vs PBS/BSA-treated BALB/c mice were also examined by slit lamp and histopathologically at 7 days p.i. These data are presented in Figures 3 and 4. The cornea of rIL-12-treated mice (Figures 3a and 4a) had perforated with numerous inflammatory cells persisting in the cornea and the anterior chamber (Figure 3a), while the cornea of PBS/BSA-treated mice exhibited only slight opacity (Figure $3 b$ ) with few to no inflammatory cells detectable histopathologically (Figure $4 b$ ).

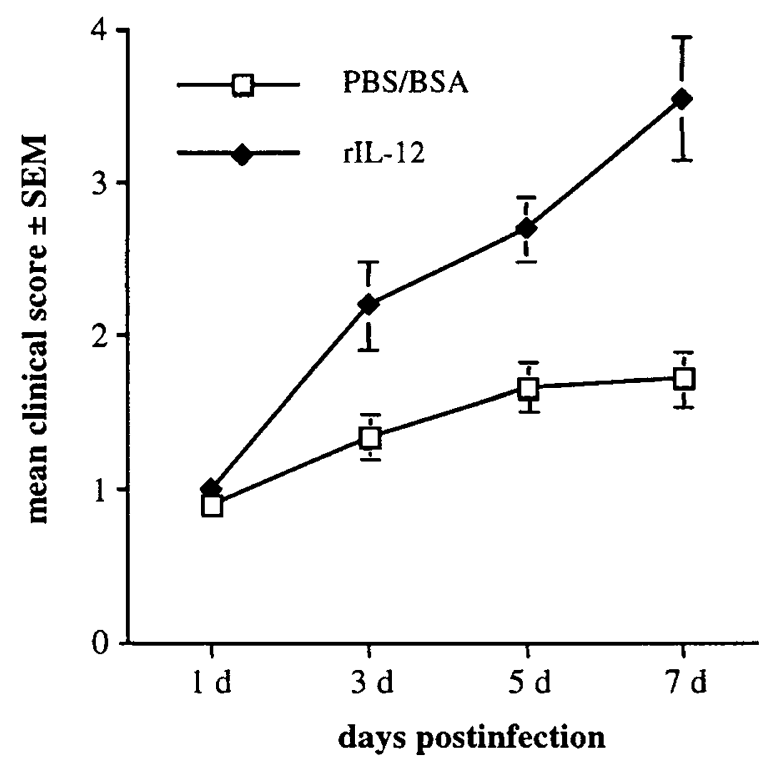

Figure 2 Ocular disease response in rIL-12 and PBS/BSAtreated BALB/c mice. After P. aeruginosa infection, ocular disease grades were averaged at individual times p.i. Results are reported as mean clinical score \pm SEM. Significant differences were observed at 3,5 , and 7 days p.i. $(P=0.15,0.02,0.002$, and 0.001 at $1,3,5$, and 7 days p.i., respectively).

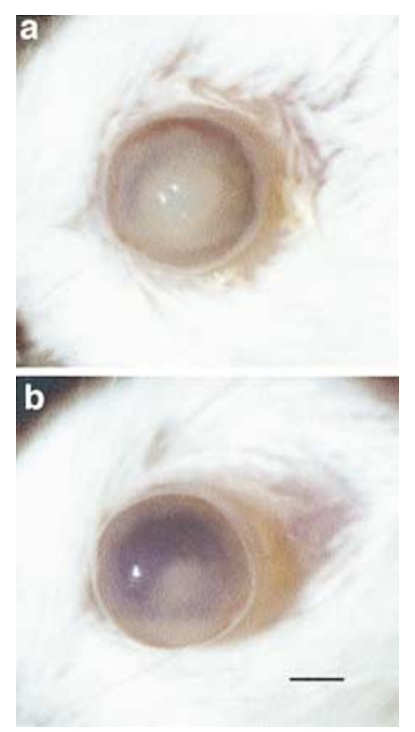

Figure 3 Slit-lamp photomicrographs of P. aeruginosa-infected corneas in rIL-12 vs PBS-BSA-treated BALB/c mice. Representative eyes from both groups of mice were photographed at 7 days p.i. using slit lamp (final magnification $\times 5$ ). Corneal perforation was evident in the eye of an rIL-12-treated animal (a), whereas less corneal opacity was observed in a PBS-BSA-treated control eye (b) $(\mathrm{bar}=1 \mathrm{~mm})$.
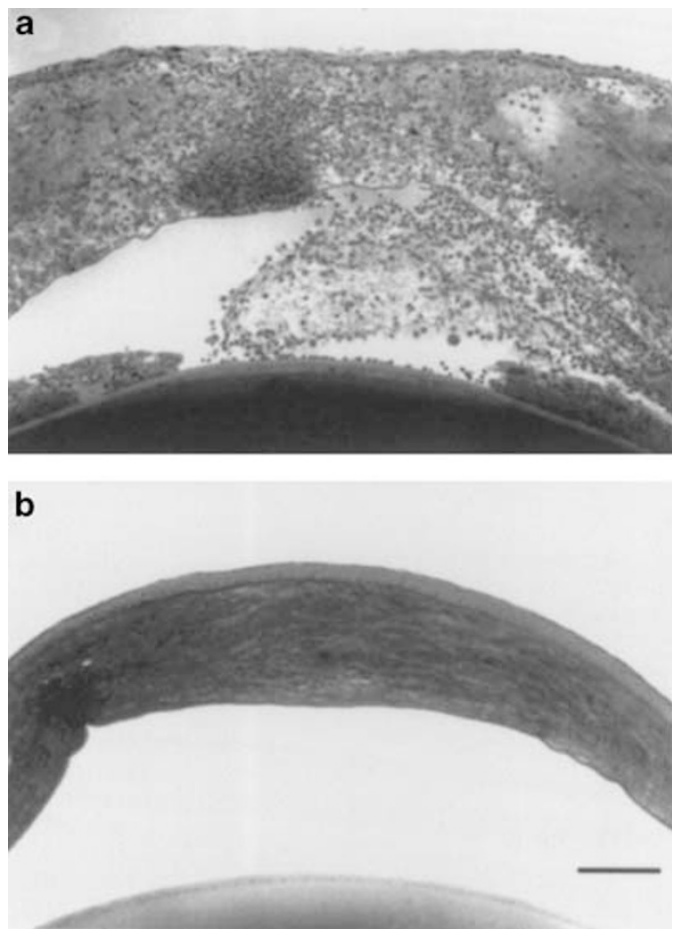

Figure 4 Light microscopic histopathology of $P$. aeruginosainfected cornea from BALB/c mice treated with rIL-12 (a) or PBS-BSA (b) at 7 days p.i. The eyes of rIL-12-treated animals exhibited corneal swelling and a heavy PMN infiltrate in the corneal stroma and anterior chamber, whereas only a slight corneal swelling and a minimal inflammatory infiltrate was observed in the PBS-BSA-treated eye (b). Magnification $\times 72$ (bar $=125 \mu \mathrm{m}$ ). 
IFN- $\gamma$ and TNF- $\alpha$ expression in corneas of rIL-12-treated $B A L B / c$ mice

We next used RT-PCR to test mRNA levels for IFN- $\gamma$ and TNF- $\alpha$ in rIL-12 vs PBS/BSA-treated BALB/c mice. Expression levels for IFN- $\gamma$ (Figure 5) and TNF- $\alpha$ (Figure 6) mRNA were significantly increased $(P=0.006$, and 0.04 at 3 and 5 days p.i., respectively, for IFN- $\gamma$; $P=0.005$ and 0.03 at 3 and 5 days p.i., respectively, for TNF- $\alpha$ ) in the corneas of rIL-12-treated when compared with vehicle-treated $B A L B / c$ mice.

\section{IL-4 mRNA expression in corneas of rIL-12-treated $B A L B / c$ mice}

As a pleiotropic Th2-type cytokine, IL-4 drives the development of Th2 T cells and is considered a prototypic anti-inflammatory cytokine associated with humoral immunity. Since IL-4 mRNA transcripts were constitutively expressed in the cornea of BALB/c mice (data not show), we next tested for the level of IL-4 mRNA expression in rIL-12 vs vehicle-treated mice after infection using RT-PCR (Figure 7). Decreased mRNA expression levels for IL-4 were observed at 3 and 5 days p.i. in the corneas of rIL-12 vs vehicle-treated mice, but the decrease was significant only at 3 days p.i. $(P=0.0004$ and 0.11 at 3 and 5 days p.i.).

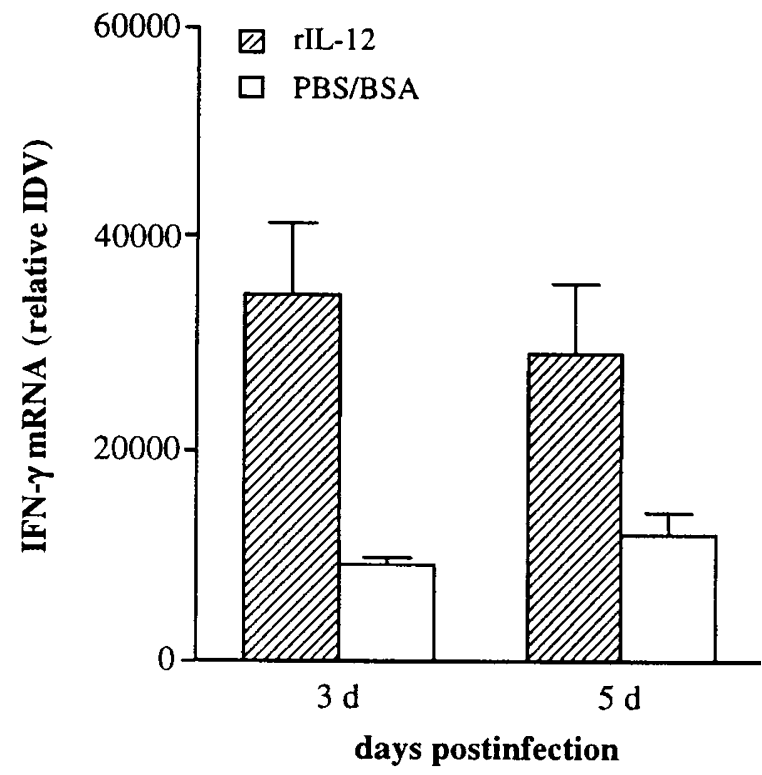

Figure 5 RT/PCR analysis of IFN $-\gamma$ mRNA expression in the cornea of BALB/c mice treated with rIL-12 vs PBS/BSA at 3 and 5 days p.i. Significant elevation in corneal levels of IFN $-\gamma$ mRNA expression in rIL-12-treated mice was observed $(P=0.006$ and 0.04 at 3 and 5 days p.i., respectively) when compared with corneal levels in PBS/BSA-treated mice.

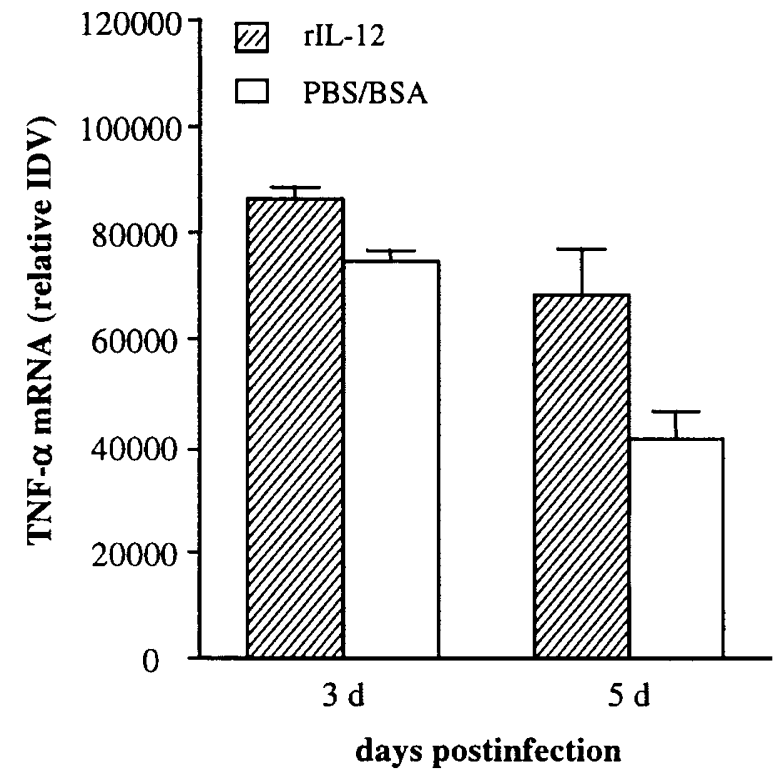

Figure 6 TNF- $\alpha$ mRNA expression in the corneas of rIL-12 vs PBS/BSA-treated BALB/c mice at 3 and 5 days p.i. Values represent the mean $\pm S E M$, and significant differences were observed ( $P=0.005$ and 0.03 at 3 and 5 days p.i., respectively).

\section{rIL-4-treated B6 mice}

To test the biological relevancy of the above data indicating that IL-4 may be associated with development

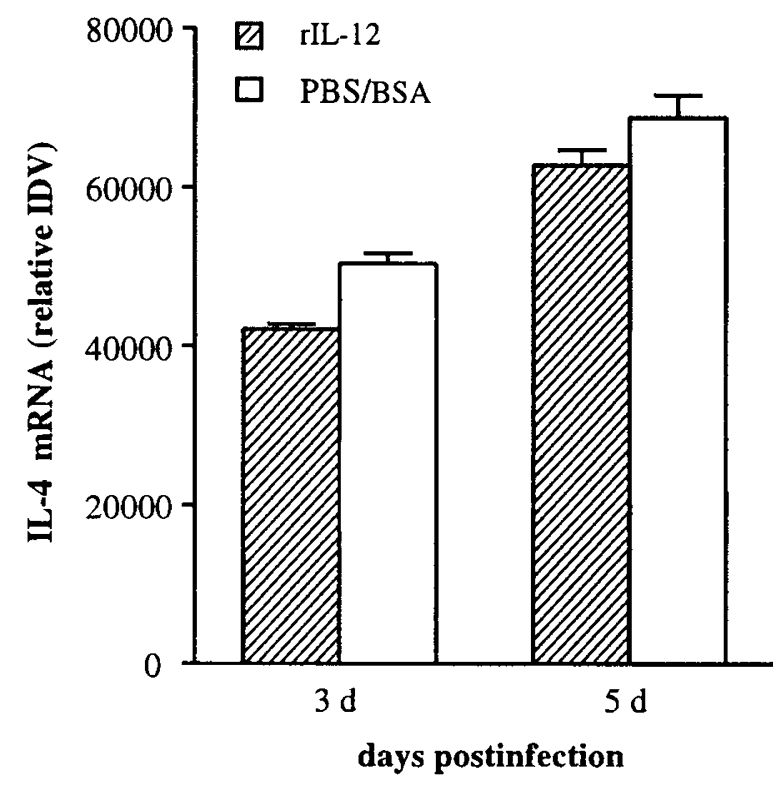

Figure 7 RT/PCR analysis of IL-4 mRNA expression in the corneas of rIL-12 vs PBS/BSA-treated BALB/c mice at 3 and 5 days p.i. Values represent the mean $\pm S E M$, and significant differences were observed at $3(P=0.0004)$, but not at 5 days p.i. $(P=0.11)$. 
of resistance, we injected susceptible B6 mice with rIL-4 to determine if the cytokine could attenuate ocular disease after $P$. aeruginosa challenge. Although a significant difference was observed in mean clinical scores (Figure 8) between rIL-4 vs PBS/BSA-treated mice at 3 days p.i. $(P=0.2878,0.0345$, and 0.0544 , at 1,3 , and 5 days p.i., respectively), the final outcome (perforation) was not changed by injection of rIL-4. Slit-lamp photography (Figure 9) confirmed the perforation response in rIL-4- as well as in vehicle-treated B6 mice. Corneas from rIL-4 vs vehicle-treated B6 mice were also examined histopathologically. These data are presented in Figure 10. At 5 days p.i., the cornea of rIL-4-treated (Figure 10a) as well as vehicle-treated B6 mice (Figure 10b) had thinned extremely and/or were perforated with numerous inflammatory cells persisting in the cornea and the anterior chamber.

\section{Discussion}

Previous studies from this laboratory indicated that in BALB/c mice, a Th2-dominated response was associated with corneal healing (resistance) following $P$. aeruginosa infection ${ }^{2}$ and that IL-12 p40 mRNA was not detectable at any time after infection in the cornea of these mice. ${ }^{8}$ Further studies showed that several other mouse strains favouring development of a Th2-type response were resistant to corneal infection, whereas strains favoring

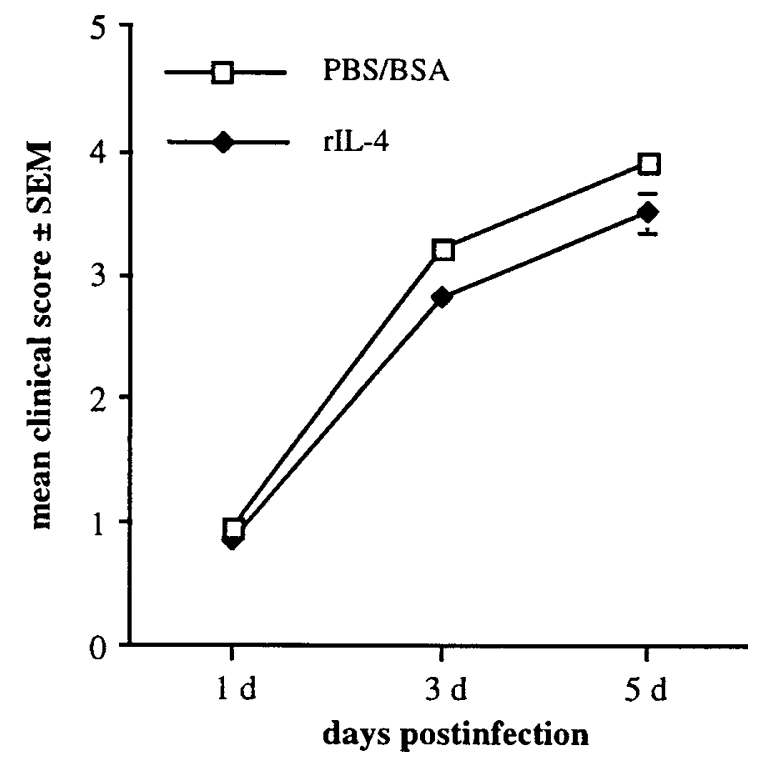

Figure 8 Ocular disease response in rIL-4 vs PBS/BSA-treated B6 mice. After $P$. aeruginosa infection, ocular disease grades were averaged at individual times p.i. Results are reported as mean clinical score \pm SEM. A significant difference was observed only at 3 days p.i. $(P=0.2878,0.0345$, and 0.0544 at 1,3 , and 5 days p.i., respectively).

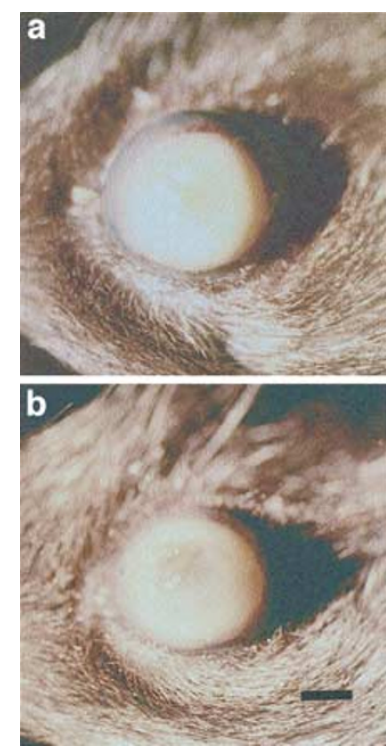

Figure 9 Slit-lamp photomicrographs of P. aeruginosa-infected corneas in rIL-4 and PBS-BSA-treated B6 mice. Representative eyes from both groups of mice were photographed at 5 days p.i. using slit lamp (final magnification, $\times 5$ ). No significant difference in ocular disease $(+4$, perforation) was seen in rIL4-(a) vs PBS-BSA-(b) treated mice (bar $=1 \mathrm{~mm}$ ).

Th1 responsiveness were susceptible. ${ }^{3}$ Current work, reported herein, focused on the capability of BALB/c mice to respond to exogenous rIL-12 administration. Also addressed were the regulatory role of IL-12 in induction of IFN- $\gamma$ and TNF- $\alpha$, the effects of rIL-12 injection on IL-4 levels in cornea, and whether disease responsiveness following $P$. aeruginosa challenge was modified after rIL-4 injection.

IL-12 participates in the regulation of and influences the characteristics of the adaptive immune response. ${ }^{10}$ As a product of macrophages and other antigen presenting cells, ${ }^{11-14}$ IL-12 appears to set the stage for effective helper type-1 T-cell responses which result in IFN- $\gamma$ production and subsequent cell-mediated immunity. ${ }^{12,15-22}$ On LPS activation of phagocytic cells, accumulation of IL-12 p40 mRNA is seen within hours and then subsides. ${ }^{7,23-25}$ IFN- $\gamma$ is the predominant cytokine induced and its continued upregulation, if unchecked or unbalanced, represents a dangerous loop that leads to excess proinflammatory cytokine production and tissue toxicity. $^{7}$

To further investigate the role of IL-12 in our model system, immunostaining was used to determine if IL-12 $\mathrm{p} 40$ protein levels were constitutively upregulated in the uninfected cornea of B6 vs BALB/c mice. Surprisingly, the data showed that IL-12 p40 protein was detectable in the corneal epithelium of uninfected B6, and, predictably, not similarly detectable in BALB/c mice (Figure 1). These 

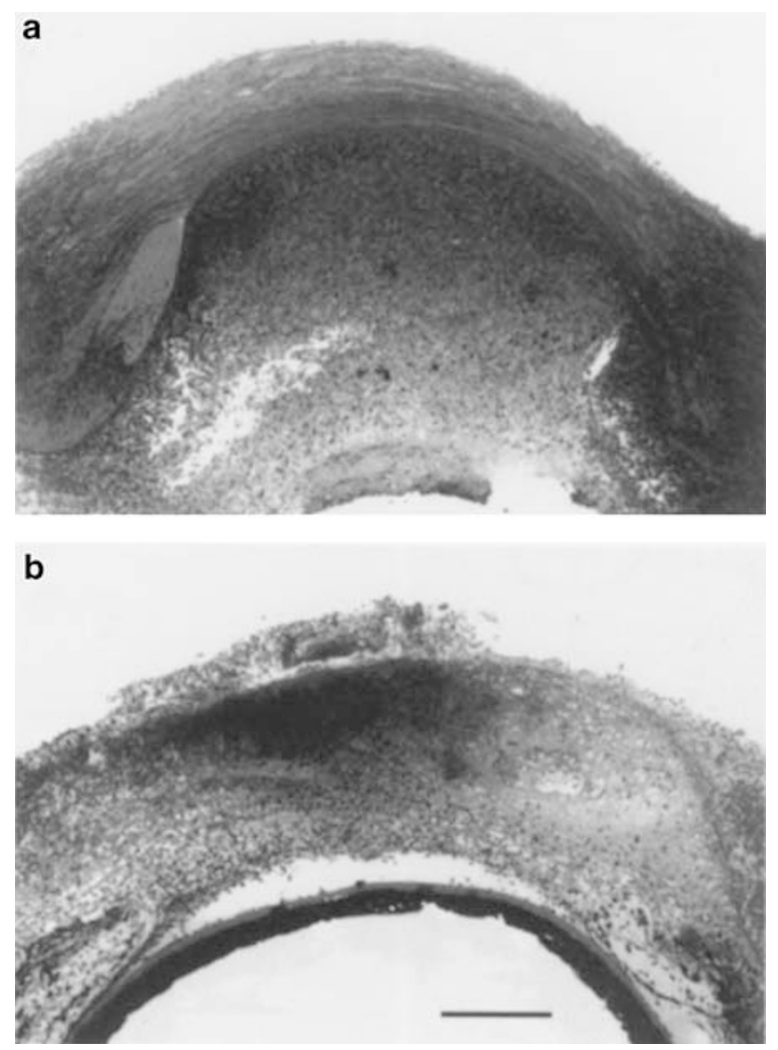

Figure 10 Light microscopic histopathology of $P$. aeruginosainfected corneas from B6 mice treated with rIL-4 (a) or PBS-BSA (b) at 5 days p.i. The corneas of both groups of mice were extremely thinned and/or near perforation. Magnification $\times 40$ (bar $=250 \mu \mathrm{m}$ ).

results suggest that epithelial overgeneration of IL-12 p40 may be a key determinate for bacterial-induced inflammation and a candidate for epithelial immune response genes that are abnormally programmed in this ocular inflammatory disease. In support of this concept, other investigators, using mouse models of lung inflammatory disease, found that IL-12 p40 overproduction by barrier epithelial cells during airway inflammation was a key intermediate for virus-induced inflammation in the lung. They also observed IL-12 p40 overexpression selectively in airway epithelial cells in asymptomatic human subjects with asthma, and immunostaining revealed concomitant increases in airway levels of IL-12 p40 and airway macrophages. ${ }^{26}$ That epithelial cells are a source of IL-12 is also supported by past studies. In this regard, others have shown IL-12 p40 mRNA expression and IL-12 release in epidermal cell preparations from skin treated with trinitrochlorobenzene. IL-12 appeared to be generated by keratinocyes, as it persisted when immune cells were depleted from the preparation. ${ }^{27}$ In the light of the above, as well as previous data from our laboratory, 7,9 we next hypothesized that administration of exogenous rIL-12 might lead to enhanced IFN- $\gamma$ and TNF- $\alpha$ production, resulting in increased pathogenesis and corneal perforation. At 1 day p.i., similar corneal disease was detected in both rIL-12- and PBS/BSA-treated BALB/c mice, but significant differences were observed at 3, 5 and 7 days p.i. At the later times, all rIL-12-injected mice exhibited an increased mean clinical score $(+2$ to +4$)$, indicating worsening of disease, while the corneas of vehicle-treated mice remained similar in appearance to the slight level of opacity observed at the initiation of infection (1-2 days p.i.). Slit lamp and histopathology confirmed the mean clinical score data and RT-PCR analysis revealed that IFN- $\gamma$ and TNF- $\alpha$ transcripts increased significantly at 3 and 5 days p.i., in the corneas of rIL-12 vs vehicle-injected mice. These data provide substantive evidence that BALB/c mice are capable of responding to exogenous IL-12 and that the cytokine can promote the susceptible phenotype through increasing IFN- $\gamma$ and TNF- $\alpha$ production in the Th2 responder mouse strain. These data are also consistent with a recent study from the laboratory, ${ }^{9}$ which revealed that IL-18 contributes to the resistance response by induction and tighter regulation of IFN- $\gamma$, and that this cytokine is required for bacterial killing and disease resolution.

Because Th2-derived cytokines such as IL-4 promote humoral immunity and may oppose Th-1-dependent activities, ${ }^{28}$ IL-4 levels were also determined in rIL-12 vs vehicle-injected BALB/c mice. Significant reduction in levels of this cytokine were observed in the recombinant protein vs vehicle-injected animals, suggesting that IL-4 may exert a protective role in this ocular model of bacterial infection. To test the in vivo relevance of these data, we next injected susceptible, B6 mice with rIL-4 to determine if exogenous cytokine could attenuate ocular disease after $P$. aeruginosa challenge. Although a significant difference was observed transiently in mean clinical scores between rIL-4 vs vehicle-treated mice, the final outcome (mean clinical score of +4 , or perforation), confirmed by slit lamp and histopathology, was not changed by injection of the cytokine. In contrast, in other studies, ${ }^{29}$ using a mouse model of $S$. aureus intravenous challenge, which, in common with our susceptible B6 mouse ocular model, is associated with increased disease that is dependent upon a Th1-type response and IFN- $\gamma$ production, it was found that IL-4 and IL-10 were protective, probably owing to regulation of IFN- $\gamma$. We have as yet not tested the anti-inflammatory effects of IL10 or IL-4 and IL-10 in combination. We would predict that either IL-10 alone, or with IL-4, may attenuate disease in our susceptible mouse model. We predict this outcome based upon previous work, which found that IL-10 was protective in the lung against $P$. aeruginosainduced pneumonia. ${ }^{30}$ Alternatively, it is also possible 
that IL-10 could enhance disease, as has been shown in a model of endotoxin-induced uveitis. ${ }^{31}$

In summary, our data show that despite their propensity for $\mathrm{Th} 2$ responsiveness, resistant BALB/c mice are capable of responding to exogenous IL-12 and can generate a Th1-type response (susceptible phenotype) through increased IFN- $\gamma$ and TNF- $\alpha$ production, concomitant with a reduction in corneal levels of IL-4. Evidence is also provided showing that exogenous injection of rIL-4 is insufficient to rescue the susceptible B6 mouse strain from corneal perforation after bacterial challenge.

\section{References}

1 Laibson PR. Pseudomonas aeruginosa. In: Fraunfelder FT. Roy FH (eds). Current Ocular Therapy. Philadelphia, PA: WB Saunders, 1990, pp 35-43.

2 Kwon B, Hazlett LD. Association of CD4 ${ }^{+}$T cell-dependent keratitis with genetic susceptibility to Pseudomonas aeruginosa ocular infection. J Immunol 1997; 159: 6283-6290.

3 Hazlett LD, McClellan S, Kwon B, Barrett R. Increased severity of Pseudomonas aeruginosa corneal infection in strains of mice designated as Th1 versus Th2 responsive. Invest Ophthalmol Vis Sci 2000; 41: 805-810.

4 O'Garra A. Cytokines induce the development of functionally heterogenous $\mathrm{T}$ helper cell subsets. Immunity 1998; 8: 275-283.

5 Abbas AK, Murphy KM, Sher A. Functional diversity of helper T lymphocytes. Nature 1996; 383: 787-793.

6 Magram JJ, Sfarra S, Connaughton D, Faherty R, Warrier D, Carvajal D et al. IL-12-deficient mice are defective but not devoid of type 1 cytokine responses. Ann NY Acad Sci 1996; 795: 60-70.

7 Hazlett LD, Rudner XL, McClellan SA, Barrett RP, Lighvani S. Role of IL-12 and IFN- $\gamma$ in Pseudomonas aeruginosa corneal infection. Invest Ophthalmol Vis Sci 2002; 43: 419-424.

8 Huang X, McClellan SA, Barrett RP, Hazlett LD. IL-18 contributes to host resistance against infection with Pseudomonas aeruginosa through induction of IFN- $\gamma$ production. J Immunol 2002; 168: 5756-5763.

9 Hazlett LD, Moon MM, Strejc M, Berk RS. Evidence for $\mathrm{N}$-acetylmannoamine as an ocular receptor for P. aeruginosa adherence to scarified cornea. Invest Ophthalmol Vis Sci 1987; 28: 1978-1985.

10 Locksley RM. Interleukin-12 in host defense against microbial pathogens. Proc Natl Acad Sci USA 1993; 90: 5879-5880.

11 D'Andrea AM, Rengaraju NM, Valiante J, Chehimi M, Kubin M, Aste-Amezaga SH et al. Production of natural killer cell stimulatory factor (NKSF/IL-12) by peripheral blood mononuclear cells. J Exp Med 1992; 176: 1387-1398.

12 Hsieh CS, Macatonia SE, Tripp CS, Wolf SF, O'Garra A, Murphy KM. Development of Th1 CD4 + T cells through IL-12 produced by Listeria-induced macrophages. Science 1993; 260: 547-549.

13 Mengel JL, DarDe L, DarDe GM, Delgacto M, Nomizo A, Silva JS et al. An activated murine B cell lymphoma line
(A-20) produces a factor-like activity which is functionally related to human natural killer cell stimulatory factor. Eur J Immunol 1992; 22: 3173-3178.

14 Yoshida A, Koide Y, Uchijima M, Yoshida TO. IFN- $\gamma$ induces IL-12 mRNA expression by murine macrophage cell line, J774. Biochem Biophys Res Commun 1994; 198: 857-861.

15 Seder RA, Gazzinelli R, Sher A, Paul WE. Interleukin 12 acts directly on $\mathrm{CD} 4+\mathrm{T}$ cells to enhance priming for interferon $\gamma$ production and diminished interleukin 4 inhibition of such priming. Proc Natl Acad Sci USA 1993; 90; 10188-10192.

16 Wolf SF, Temple PA, Kobayashi M, Young D, Dicig M, Lowe L et al. Cloning of cDNA for natural killer cell stimulatory factor, a heterodimeric cytokine with multiple biologic effects on T and natural killer cells. J Immunol 1991; 146: 3074-3081.

17 Chan SH, Perussia B, Gupta JW, Kobayashi M, Pospisil M, Young HA et al. Induction of IFN- $\gamma$ production by NK cell stimulatory factor (NKSF): characterization of the responder cells and synergy with other inducers. J Exp Med 1991; 173: 869-879.

18 Manetti R, Parronchi P, Giudizi MG, Piccinni M-P, Maggi E, Trinchieri G et al. Natural killer stimulatory factor (NKSF/ IL-12) induces T helper type 1 (Th1)-specific immune responses and inhibits the development of IL-4 producing Th cells. J Exp Med 1993; 177: 1199-1204.

19 Manetti R, Gerosa F, Giudizi MG, Biagiotti R, Paronchi P, Piccinni $\mathrm{M}$ et al. Interleukin 12 induces stable priming for interferon- $\gamma(\mathrm{IFN}-\gamma)$ production during differentiation of human T helper (Th) cells and transient IFN- $\gamma$ production in established Th2 cell clones. J Exp Med 1994; 179: $1273-1283$.

20 Wu CY, Demeure D, Kiniwa M, Gately M, Delespesse G. IL-12 induces the production of IFN- $\gamma$ by neonatal human CD4 T cells. J Immunol 1993; 151: 1938-1949.

21 Finkelman FD, Madden KB, Cheveer AW, Katona IM, Morris SC, Gately MK et al. Effects of interleukin 12 on immune responses and host protection in mice infected with intestinal nematode parasites. J Exp Med 1994; 179: 1563-1572.

22 Morris SC, Madden KB, Adamovicz JJ, Gause WC, Hubbard BR, Gately MK et al. Effects of IL-12 on in vivo cytokine gene expression and Ig isotype secretion. J Immunol 1994; 152: 1047-1056.

23 Trinchieri G, Gerosa F. Immunoregulation by interleukin-12. J Leukoc Biol 1996; 59: 505-511.

24 Gazzinelli RT, Wysocka M, Hayashi S, Denkers EY, Hieny S, Caspar P et al. Parasite induced IL-12 stimulates early IFN- $\gamma$ synthesis and resistance during acute infection with Toxoplasma gondii. J Immunol 1994; 153: 2533-2543.

25 Vieira LQ, Hondowica BD, Afonso LC, Wysocka M, Trinchieri G, Scott P. Infection with Leishmania major induces interleukin-12 production in vivo. Immunol Lett 1994; 40: 157-161.

26 Walter MJ, Kajiwara N, Karanja P, Castro M, Holtzman MJ. Interleukin $12 \mathrm{p} 40$ production by barrier epithelial cells during airway inflammation. J Exp Med 2001; 193: 339-351.

27 Muller G, Saloga J, Germann T, Bellinghausen I, Mohamadzadeh M, Knop J et al. Identification and induction of human keratinocyte-derived IL-12. J Clin Invest 1994; 94: 1799-1805. 
28 Boehm U, Klamp U, Groot M, Howard JD. Cellular responses to interferon- $\gamma$. Annu Rev Immunol 1997; 15: 749-795.

29 Sasaki S, Nishikawa S, Miura T, Mizuki M, Yamada K, Madarame $\mathrm{H}$ et al. Interleukin- 4 and interleukin-10 are involved in host resistance to Staphylococcus aureus infection through regulation of gamma inferferon. Infect Immun 2000; 68: 2424-2430.
30 Sawa T, Corry DB, Cropper MA, Ohara M, Kurahashi K, Weiner-Kronish JP. IL-10 improves lung injury and survival in Pseudomonas aeruginosa pneumonia. J Immunol 1997; 159: 2858-2866.

31 Rosenbaum JT, Angell EM. Paradoxical effects of interleukin-10 in endotoxin induced uveitis. J Immunol 1995; 155: 4090-4094. 